\title{
March 2017 Critical Care Case of the Month
}

\author{
Kyle J. Henry, MD \\ Banner University Medical Center Phoenix \\ Phoenix, AZ USA
}

\section{History of Present IIIness}

A 50-year-old man presented to the emergency room via private vehicle complaining of 5 days of intermittent chest and right upper quadrant pain. Associated with the pain he had nausea, cough, shortness of breath, lower extremity edema, and palpitations.

\section{Past Medical History, Social History, and Family History}

He had a history of hypertension and diabetes mellitus but was on no medications and had not seen a provider in years. He was disabled from his job as a construction worker. He had smoked a pack per day for 30 years. He was a heavy daily ethanol consumer. He had an extensive family history of diabetes.

\section{Physical Examination}

- Vitals: T 36.4 C, pulse 106/min and regular, blood pressure $96 / 69 \mathrm{~mm} \mathrm{Hg}$, respiratory rate 19 breaths/min, SpO2 98\% on room air

- Lungs: clear

- Heart: regular rhythm without murmur.

- Abdomen: mild RUQ tenderness

- Extremities: No edema noted.

\section{Electrocardiogram}

His electrocardiogram is show in Figure 1.

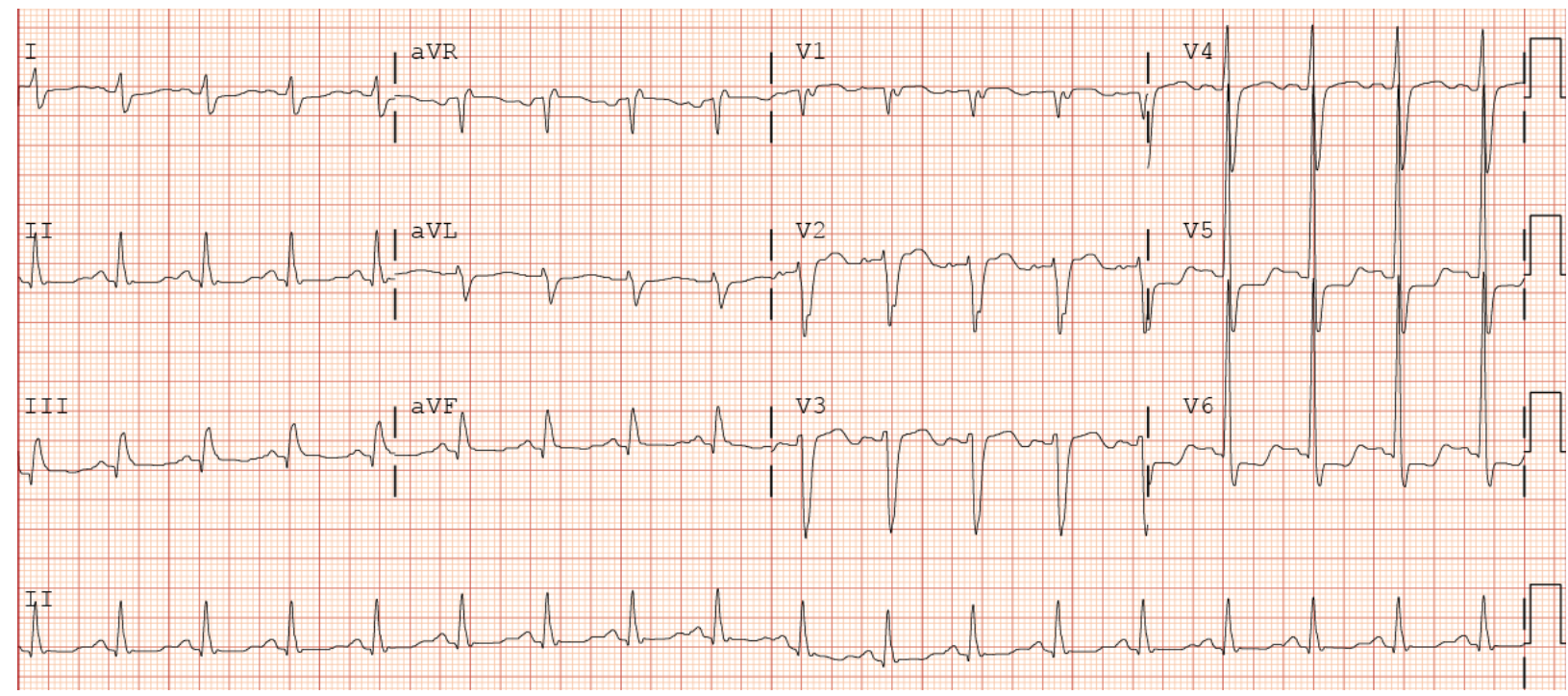

Figure 1. Admission electrocardiogram. 


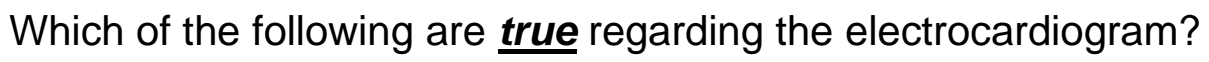

1. The lack of $Q$ waves in $V 2$ and $V 3$ excludes an anteroseptal myocardial infarction

2. The S1Q3T3 patter is diagnostic of a pulmonary embolism

3. There are nonspecific ST and T wave changes

4. 1 and 3

5. All of the above 


\section{Correct!}

\section{There are nonspecific ST and T wave changes}

There are no specific changes on the electrocardiogram. Q waves in V1-V3 are characteristic of an anteroseptal myocardial infarction but their absence does not exclude that diagnosis. The S1Q3T3 pattern has been described with pulmonary embolism but is nonspecific and most pulmonary emboli are not associated with this pattern (1). There are diffuse nonspecific ST and T wave changes present.

Which of the following should be done at this time?

1. Administer crystalloid fluids

2. Chest X-ray

3. Troponins

4. 1 and 3

5. All of the above 


\section{Correct! \\ 5. All of the above}

The cause of the patient's symptoms is not totally clear. A chest $x$-ray is indicated because of his shortness of breath and is shown in Figure 2.

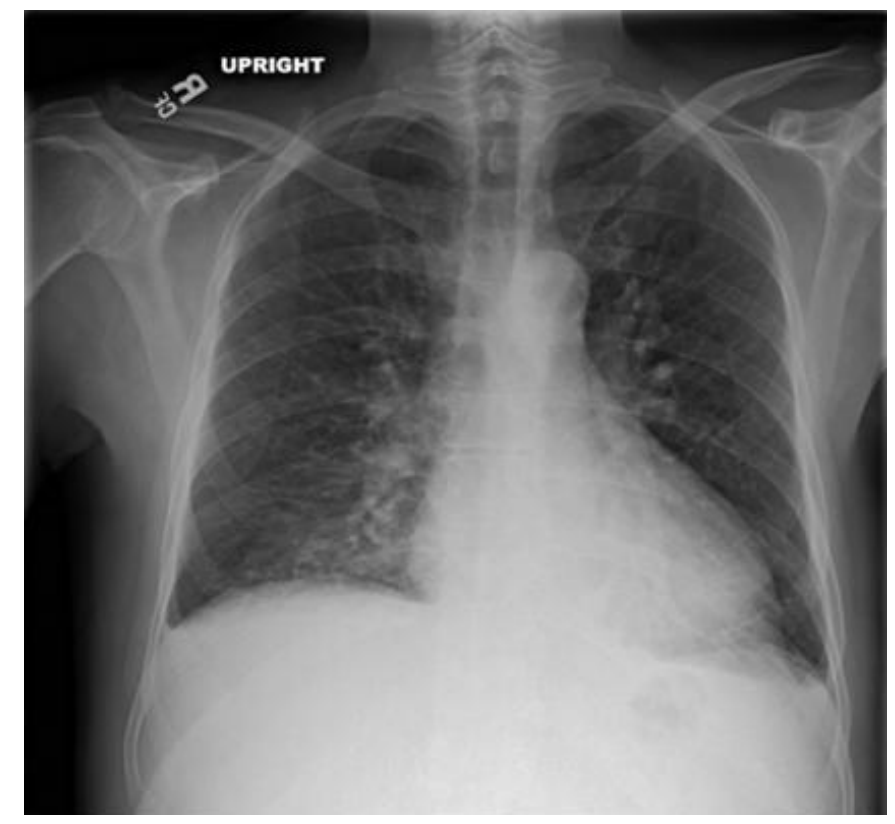

Figure 2. Initial portable chest x-ray taken in the emergency room.

Crystalloid fluids are indicated because of the patient's hypotension. His troponins were mildly elevated at $0.86 \mathrm{ng} / \mathrm{ml}$ (normal $<0.01 \mathrm{ng} / \mathrm{ml}$ ). Additional laboratory obtained include:

- Electrolytes $\left(\mathrm{Na}^{+} 122, \mathrm{Cl}^{-} 76, \mathrm{~K}^{+} 3.6, \mathrm{HCO}^{-} 27\right)$

- Lactic acid $5.5 \mathrm{mmol} / \mathrm{L}$ (Normal $<1 \mathrm{mmol} / \mathrm{L})$

- AST $760 \mathrm{U} / \mathrm{L}$, ALT $913 \mathrm{U} / \mathrm{L}$, alkaline phosphatase $181 \mathrm{IU} / \mathrm{L}$ (all modestly elevated)

- INR 20.1

- D-dimer $9.18 \mathrm{mcg} / \mathrm{mL}$ (normal $<0.5 \mathrm{mcg} / \mathrm{mL}$ )

Which of the following is/are true?

1. A point of care ultrasound may be useful in diagnosing the cause of the hypotension

2. The elevated D-dimer is diagnostic of a pulmonary embolism

3. The elevated lactic acid likely indicates inadequate tissue perfusion

4. 1 and 3

5. All of the above 


\section{Correct!}

\section{1 and 3}

D-dimers are sensitive but not specific (2). In other words, a deep venous thrombosis (or its complication pulmonary embolism) is unlikely with a normal D-dimer but an elevated D-dimer is not diagnostic of pulmonary embolism. In this situation with hypotension, the elevated lactic acid likely indicates inadequate tissue perfusion. A point of care ultrasound can be quite useful in assessing hypotension in the ICU (3).

An ultrasound was performed. The inferior vena cava was $2.8 \mathrm{~cm}$ in diameter (normal $1.5-2.5 \mathrm{~cm}$ in adults). The subcostal ultrasound of the heart is shown in figure 3.

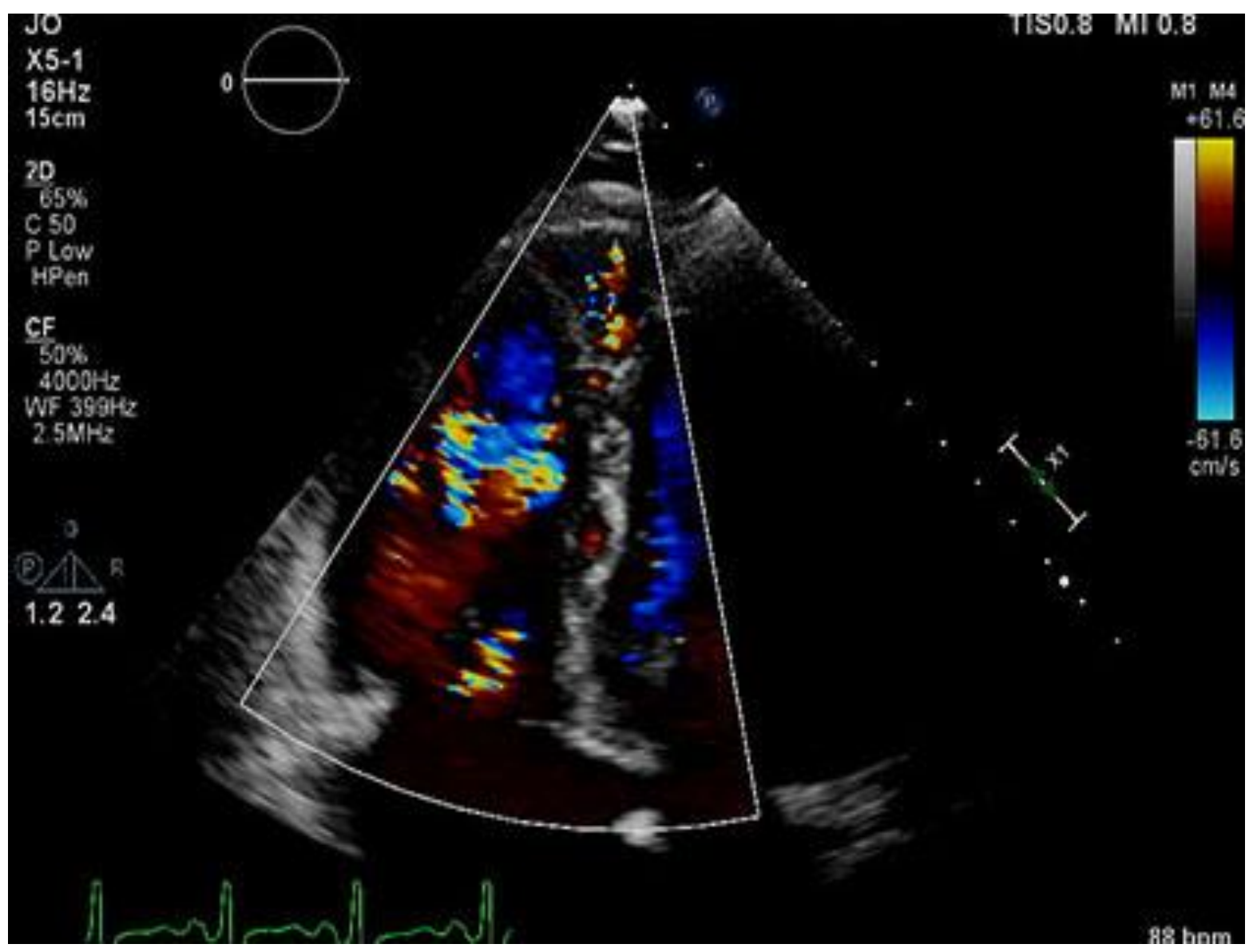

Figure 3. Subcostal ultrasound of the heart.

Which of the following is/are true?

1. The dilated inferior vena cava is consistent with volume overload

2. The left ventricle is hypokinetic

3. There is a left to right shunt at the level of the ventricles

4. 1 and 3

5. All of the above 


\section{Correct!}

\section{1 and 3}

The dilated inferior vena cava is consistent with fluid overload. This could be a failing left ventricle, however, the cardiac ultrasound shows the left ventricle to be contracting (estimated ejection fraction $>50 \%$ ) but there is a large left to right shunt at the level of the ventricles. Cardiology was consulted and they suggested a right sided heart catheterization.

\section{What should be done during the right heart catheterization?}

1. Measure the blood oxygen saturation from the right atrium, right ventricle and pulmonary artery looking for a step up in the oxygen saturation

2. Perform right ventricular angiography to demonstrate the shunt

3. Pressures measurements in the right atrium, right ventricle, pulmonary artery and pulmonary artery wedge position

4. 1 and 3

5. All of the above 


\section{Correct!}

\section{1 and 3}

Ventricular septal defects with a left to right shunt have a step up in the blood oxygen in the right ventricle which results from the mixing of the oxygenated left ventricular blood with the normally deoxygenated right ventricular blood. The results of the right heart catheterization are shown in Figure 4.

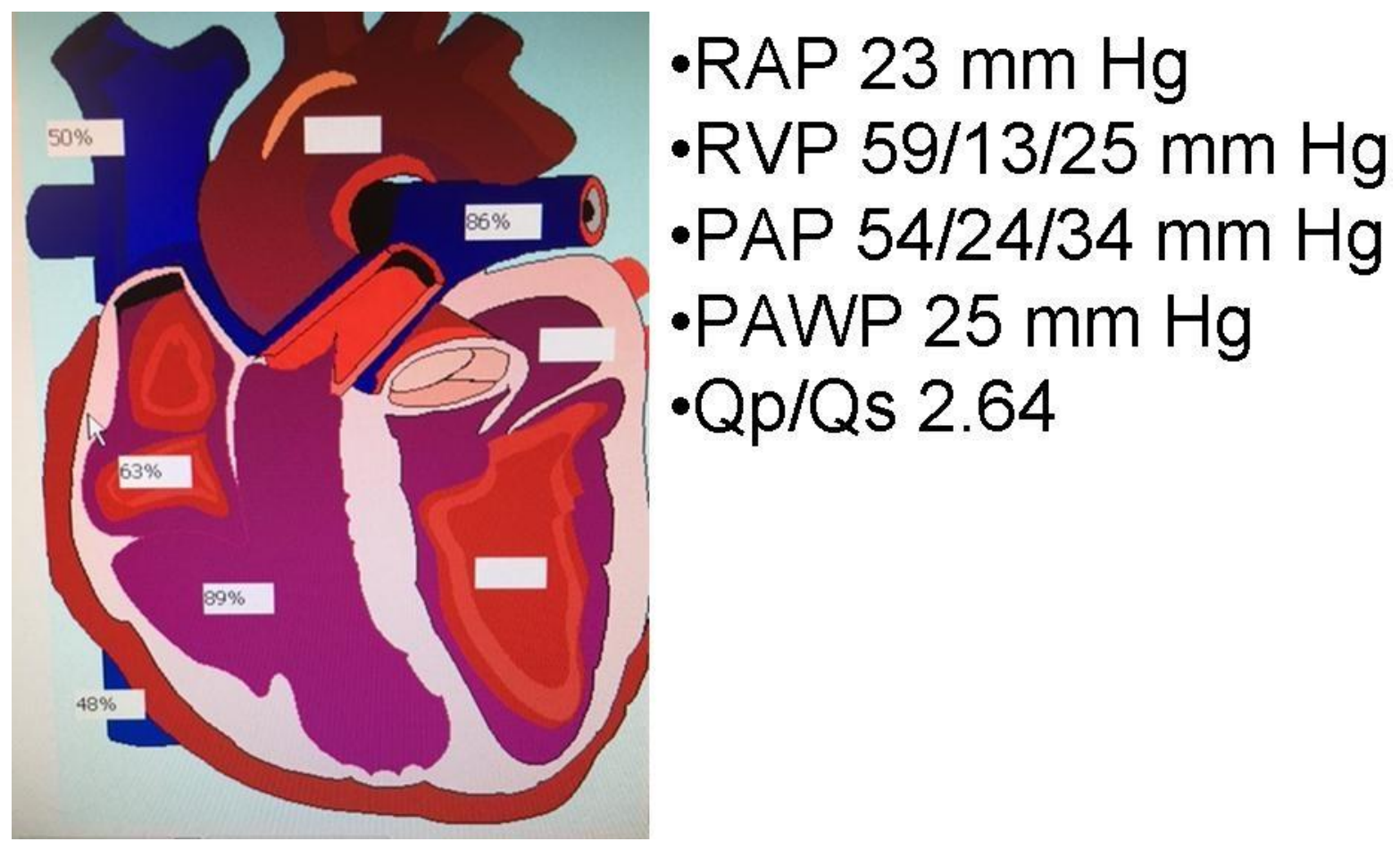

Figure 4. Right ventricular oxygen saturations and pressures.

What should be done next?

1. Consult cardiology for percutaneous VSD closure

2. Consult thoracic surgery for VSD repair

3. Medically support the patient with afterload reduction, inotropes and vasopressors

4. 1 and 3

5. All of the above 


\section{Correct! \\ 5. All of the above}

Both cardiology and thoracic surgery were consulted by thought that any intervention should be postponed because the post-MI myocardium would likely be too fragile for early intervention. Waiting 3-6 weeks was recommended to allow for scaring. In the meantime, supportive therapy was performed with afterload reduction, inotropes and vasopressors. Unfortunately, the patient decompensated and died.

Septal rupture resulting in a VSD after a myocardial infarction are unusual occurring in only $0.2 \%$ of patients (4). These usually occur within 3-5 days of the myocardial infarction. Our patient probably had a large infarction about 5 days before admission which would explain his relatively low troponins and his presentation with septal rupture.

Unfortunately, septal rupture can be an ominous sign. About $20 \%$ of patients also have concomitant rupture of the chordae tendineae resulting in mitral regurgitation (4). Mortality rates increase the longer a procedure to the VSD is delayed but the mortality from the procedure also declines with delay $(5,6)$. In addition to medical therapy, mechanical support with an intra-aortic balloon pump or an Impella ${ }^{\circledR}$ device have been successfully used while supporting the patient until a definitive procedure can be performed $(7,8)$.

\section{References}

1. Ullman E, Brady WJ, Perron AD, Chan T, Mattu A. Electrocardiographic manifestations of pulmonary embolism. Am J Emerg Med. 2001 Oct;19(6):514-9. [CrossRef] [PubMed]

2. Crawford F, Andras A, Welch K, Sheares K, Keeling D, Chappell FM. D-dimer test for excluding the diagnosis of pulmonary embolism. Cochrane Database Syst Rev. 2016 Aug 5;(8):CD010864. [CrossRef] [PubMed]

3. Atkinson PR, McAuley DJ, Kendall RJ, et al. Abdominal and Cardiac Evaluation with Sonography in Shock (ACES): an approach by emergency physicians for the use of ultrasound in patients with undifferentiated hypotension. Emerg Med J. 2009 Feb;26(2):87-91. [CrossRef] [PubMed]

4. Birnbaum $Y$, Fishbein $M C$, Blanche $C$, Siegel RJ. Ventricular septal rupture after acute myocardial infarction. N Engl J Med. 2002 Oct 31;347(18):1426-32. [CrossRef] [PubMed]

5. Calvert PA, Cockburn J, Wynne D, et al. Percutaneous closure of postinfarction ventricular septal defect: in-hospital outcomes and long-term follow-up of UK experience. Circulation. 2014 Jun 10;129(23):2395-402. [CrossRef] [PubMed]

6. Arnaoutakis GJ, Zhao Y, George TJ, Sciortino CM, McCarthy PM, Conte JV. Surgical repair of ventricular septal defect after myocardial infarction: outcomes from the Society of Thoracic Surgeons National Database. Ann Thorac Surg. 2012 Aug;94(2):436-43; discussion 443-4. [CrossRef] [PubMed] 
7. Jones BM, Kapadia SR, Smedira NG, Robich M, Tuzcu EM, Menon V, Krishnaswamy A. Ventricular septal rupture complicating acute myocardial infarction: a contemporary review. Eur Heart J. 2014 Aug 14;35(31):2060-8. [CrossRef] [PubMed]

8. Dahlin LG, Peterzén B. Impella used for hemostasis by left ventricular unloading, in a case with left ventricular posterior wall rupture. Ann Thorac Surg. 2008 Apr;85(4):1445-7. [CrossRef] [PubMed] 